Research Article

\title{
A Study to Assess the Knowledge of Women regarding use of Zinc Supplementation with ORS in Managing Diarrhoea in a Selected Rural Community in Bhopal
}

\author{
Rakhi Patel', Linson CC \\ ${ }^{1}$ Dr Sarvapalli Radhakrishanan (SRK) University, Bhopal, Madhya Pradesh, India. \\ ${ }^{2}$ Department of Nursing, Sarvapalli Radhakrishnana University, Bhopal, Madhya Pradesh, India. \\ DOI: https://doi.org/10.24321/2348.2141.202105
}

\section{I $\quad \begin{array}{lllll}\mathbf{N} & \mathbf{F} & \mathbf{O}\end{array}$}

\section{Corresponding Author:}

Rakhi Patel, Department of Nursing, Sarvapalli Radhakrishanan (SRK) University, Bhopal, Madhya Pradesh, India.

E-mail Id:

rakhiridhi17@gmail.com

Orcid Id:

https://orcid.org/0000-0003-2125-0511

How to cite this article:

Patel R, Linson CC. A Study to Assess the Knowledge of Women regarding use of Zinc Supplementation with ORS in Managing Diarrhoea in a Selected Rural Community in Bhopal. Trends Nurs Adm Edu. 2021;10(2):1-5.

Date of Submission: 2021-07-22

Date of Acceptance: 2021-08-14

\section{$\begin{array}{llllllll}\mathbf{A} & \mathbf{B} & \mathbf{S} & \mathbf{T} & \mathbf{R} & \mathbf{A} & \mathbf{C} & \mathbf{T}\end{array}$}

Background: Diarrhoea is the third most common reason for youth mortality in India. More than 2 million kids die because of loose bowels and parchedness consistently. Diarrhoeal sickness causes hefty monetary pressure on the healthcare administration. Much consideration has been given to diarrhoeal sickness and its administration in the course of this decade. Oral rehydration strategy and zinc supplementation have proved to be extremely helpful in this aspect.

Methods: A descriptive approach has been utilised to evaluate the knowledge of women in regards to the use of zinc supplementation with ORS in overseeing diarrhoea. Purposive sampling procedure was used to choose 100 mothers. The researcher assessed the knowledge of the study subjects regarding the advantages of zinc with ORS using a structured knowledge questionnaire. The gathered information was assessed by graphic and inferential measurements.

Results: $63 \%$ of women got average score and $1 \%$ of women obtained very good score, $2 \%$ of women obtained poor score and not even a single woman got very poor score. The mean knowledge score of women regarding the benefits of zinc with ORS in managing diarrhoea was 17.24.

Conclusion: Women are the greatest health workers who make all the possible efforts to provide their families with everything. If women possess the required knowledge, they themselves would leave no stone unturned to use the various preventive measures and get rid of diarrhoea for the health of their family members. So, the knowledge of women related to health services needs to be updated and improved.

Keywords: Assess, Knowledge, Zinc Supplementation, ORS 


\section{Introduction}

Youth and kids are considered as a country's remarkably significant resource. With the same belief, the approach of the state is to offer sufficient assistance to kids all through their development and improvement. Kid's wellbeing is regarded as the most prominent need throughout the life of a person and numerous wellbeing programmes have been executed with an aim to decrease youth and kids' mortality. ${ }^{4}$

It is important to assess youngster's wellbeing, social qualities, and social strategy in the local area. The energetic work of neighbourhood zone especially from families is an obvious prerequisite. ${ }^{2}$ Diarrhoea is the third commonest reason for youth mortality in India. More than 2 million kids die because of the looseness of bowels and lack of hydration consistently. Diarrhoeal infections cause a substantial financial burden on the healthcare administration. Much thought has been given to strongly diarrhoeal ailment and its organisation since the last few years, which has overpowered zinc supplementation.

Zinc supplementation is a basic new medication for treating diarrhoeal illness among kids. Various ongoing researches recommend that providing zinc along with ORS can lower the duration of diarrhoeal illness.

A continuing lack of clean water and adequate sanitation in many parts of the world has led to diarrhoea being the leading cause of death among infants and young children in low and middle-income countries. Every year more than a million children under five years of age succumb to the fluid loss and dehydration associated with majority of diarrhoea related deaths. It is estimated that we lose $13 \%$ of the population to ill-health, disability, and early deaths caused by diarrhoea. ${ }^{2}$

Diarrhoea refers to loose, watery stools that occur more frequently than usual. It is usually caused by a virus, or sometimes, contaminated food. Less frequently, it can be a sign of some other disorder, such as inflammatory bowel disease or irritable bowel syndrome. ${ }^{3}$

Oral rehydration is a notable and generally straightforward treatment approach. ${ }^{8-14}$ Zinc supplementation has been found to decrease the duration and seriousness of diarrhoeal illness and the probability of resulting contaminations for 2 months.

Zinc is a basic new medication for treating loose bowels, especially in the developing world. It is a safe and successful treatment choice that can significantly reduce the requirement for hospitalisation. It might likewise reduce the future chances of diarrhoea for as long as a quarter of a year. ${ }^{1}$

ORS, when given with zinc supplementation, offers significantly better results for the treatment of loose stools.
It can be easily administered by a medical services supplier or at home by guardians and parental figures. It brings down stool volume by almost $25 \%$ and causes nearly $30 \%$ less vomiting. ${ }^{1}$ WHO and UNICEF both suggest using the low osmolarity solution. Looseness of bowels with serious zinc inadequacy has been seen in youngsters in undeveloped nations. Zinc is a fundamental micronutrient for human development. Zinc supplements, if given for 10-14 days, bring down the frequency of loose stools and its likelihood for the next 2 to 3 months. Due to this, WHO and UNICEF suggested giving $10 \mathrm{mg}$ of zinc to babies under a half-yearold every day and $20 \mathrm{mg}$ to kids aged more than a half year for $10-14$ days. $^{5}$

Administration of India under its Conceptive and Kid Wellbeing Project particularly underscored after improving kid endurance exercises including upgrading the ORS use rate through proper conduct change and making new ORS and zinc broadly and effectively accessible at networks and wellbeing focuses/ offices. It was also established that simple admittance to zinc with ORS and information about its utilisation are critical to the decrease of passings and seriousness because of looseness of the bowels.

\section{Methods}

Research Design: A descriptive research design was used for the present study.

Study Duration: One month.

Study Setting: The study was conducted in the Goalgaw community which comes under Nayapura Primary Health Center, Bhopal.

Variables: The study used demographic variables like age, types of family, education status, religion, and previous knowledge related to managing diarrhoea.

Sample: 100 women residing at Goalgaw rural community which comes under Nayapura PHC, Bhopal.

Sampling Technique: Purposive sampling technique was used to select the sample.

\section{Inclusion Criteria}

The women who fulfilled the following conditions were included in the study:

- Women who were housewives

- Women who were willing to participate in the study

- Women who were available at the time of data collection

\section{Exclusion Criteria}

The women who were working and/ or were busy at the time of study were excluded from the study.

Data Collection Tool: A structured knowledge questionnaire was used in this study. 


\section{Data Collection Methods}

1. Formal permission was obtained from the medical officer in Primary Health Centre to conduct the study. Permission was also taken from the panchayat's president prior to data collection.

2. Investigator introduced herself and developed a rapport with the subjects. The investigator conducted the main study after getting consent from 100 samples by purposive sampling method at Nayapura, Bhopal.

3. A validated structured interview was conducted to collect data about knowledge of prevention and treatment of diarrhoea since this technique is feasible and suitable to collect data from all the participants. A total of 100 women were selected for the study. Data were collected from the sample by administering a structured interview schedule after obtaining consent from the participants. Each day around 4-5 women were interviewed and each session lasted for 3040 minutes. After this, 3-5 minutes were utilised by the investigator to provide verbal guidelines to the respondents regarding zinc supplements with ORS in managing diarrhoea, its cause, signs and symptoms, complications, and its prevention and control. It took one month to complete the study.

\section{Analysis and Interpretation}

- Interrelated data was illustrated in the form of Tables

- $\quad$ Frequency and percentage distribution were used to analyse the demographic variables

- Mean and standard deviation were used to determine the knowledge of women regarding zinc supplementation with ORS in managing diarrhoea

- Chi-square test was used for finding the association of knowledge of women and selected demographic variables

\section{Results}

Table 1 depicts that maximum women (38\%) belonged to the age group of $26-30$ years, $32 \%$ belonged to the age group of $20-25$ years, $15 \%$ were in the age group of $31-35$ years, and $15 \%$ were in the age group of $36-40$ years. According to the type of family, $19 \%$ of the subjects belonged to nuclear families, and $81 \%$ belonged to joint families. Regarding educational status, maximum (78\%) subjects had not received any formal education, $15 \%$ had received primary education, $3 \%$ had received secondary education, $2 \%$ had received higher secondary education, and the rest (2\%) were graduates. According to religion, $88 \%$ of participants were Hindu, $12 \%$ were Muslim, and no one belonged to Christianity or any other religion. Regarding previous knowledge of treatment and management of diarrhoea, $78 \%$ were aware of how to treat and manage it, while $22 \%$ were not aware of it.

Table 2 shows the frequency and percentage distribution of the level of knowledge of women regarding diarrhoea. $0 \%$ of women obtained very poor score $(0-20 \%), 2 \%$ of women got poor score (21-40\%), $63 \%$ of women obtained average score (41-60\%), 34\% of women obtained good score (61-80\%), and $1 \%$ of women obtained very good score (81$100 \%)$. The data present in this table clearly indicate that 63 women belonging to the rural community had average knowledge regarding managing diarrhoea.

Table I.Frequency and Percentage of Women as per their Demographic Variables

\begin{tabular}{|c|c|c|c|}
\hline S. No. & Variables & Frequency & Percentage \\
\hline \multirow{5}{*}{1.} & \multicolumn{3}{|l|}{ Age (years) } \\
\hline & $20-25$ & 32 & 32 \\
\hline & $26-30$ & 38 & 38 \\
\hline & $31-35$ & 15 & 15 \\
\hline & $36-40$ & 15 & 15 \\
\hline \multirow{3}{*}{2.} & \multicolumn{3}{|l|}{ Type of family } \\
\hline & Nuclear & 19 & 19 \\
\hline & Joint & 81 & 81 \\
\hline \multirow{6}{*}{3.} & \multicolumn{3}{|l|}{ Educational status } \\
\hline & No formal education & 78 & 78 \\
\hline & Primary education & 15 & 15 \\
\hline & Secondary education & 3 & 3 \\
\hline & Higher secondary & 2 & 2 \\
\hline & Graduate & 2 & 2 \\
\hline
\end{tabular}




\begin{tabular}{|c|c|c|c|}
\hline \multirow{4}{*}{4.} & \multicolumn{2}{|c|}{} \\
\cline { 2 - 4 } & Heligion & 88 & 88 \\
\cline { 2 - 4 } & Muslim & 12 & 12 \\
\cline { 2 - 4 } & Christian & 0 & 0 \\
\cline { 2 - 4 } & Others & 0 & 0 \\
\hline \multirow{3}{*}{5.} & Previous knowledge related to treatment and management of diarrhoea \\
\cline { 2 - 4 } & Yes & 78 & 22 \\
\cline { 2 - 4 } & No & 22 & 22 \\
\hline
\end{tabular}

Table 2.Frequency and Percentage Distribution of Level of Knowledge of Women

\begin{tabular}{|c|c|c|c|c|c|c|c|}
\hline S. No. & Category & Score & Percentage Score & Frequency & Percentage & Mean & SD \\
\hline 1. & Very poor & $0-6$ & $0-20$ & 0 & 0 & \multirow{5}{*}{17.24} & \multirow{5}{*}{2.7317} \\
\hline 2. & Poor & $7-12$ & $21-40$ & 2 & 2 & & \\
\hline 3. & Average & $13-18$ & $41-60$ & 63 & 63 & & \\
\hline 4. & Good & $19-24$ & $61-80$ & 34 & 34 & & \\
\hline 5. & Very good & $25-30$ & $81-100$ & 1 & 1 & & \\
\hline
\end{tabular}

\section{Discussion}

The findings of this study are similar to those of a study conducted by Patel M (2003) in Madhya Pradesh on the knowledge regarding prevention and management of diarrhoea. ${ }^{7}$ It showed that the knowledge of people regarding various aspects of managing diarrhoea was poor but was raised significantly after an educational interventional survey.

\section{Demographic Profile of Women}

The demographic profile of the participants showed that $38 \%$ of the subjects were in the age group of $26-30$ years, $81 \%$ of subjects belonged to joint families, $78 \%$ of subjects had no formal education, $88 \%$ of subjects belonged to Hindu religion, and $78 \%$ of the participants had previous knowledge regarding the management of diarrhoea. A similar study conducted by Meshram PV (2008) reported that most of the respondents belonged to the age group of $30-34$ years, out of which $46.6 \%$ were illiterate, and had a knowledge score of $7.3 \% .^{8}$

\section{Knowledge Score of Women regarding Zinc Supplementation with ORS in managing Diarrhoea}

The findings of the study revealed that 63 subjects had average knowledge regarding zinc supplementation with ORS in managing diarrhoea and the mean knowledge score of women regarding managing diarrhoea was 17.24 (and SD was 2.7317).

Association of Demographic Variables with Levels of Knowledge of Women regarding Zinc Supplementation with ORS in managing Diarrhoea

Association of demographic variables with the level of knowledge of participants was done using chi-square test. Although there was no statically significant association found between the level of knowledge and demographic variables such as educational status, religion, and previous knowledge, a significant association was found between the level of knowledge and type of family at 0.05 level. A highly significant association was found between the level of knowledge and age of women at 0.005 level. This indicates that the level of knowledge of women varies according to the type of family and age of women.

\section{Conclusion}

A woman is a nurse who takes care of the family members. Since the health of all the members of the family, including the children, is dependent on her, it is highly important that she should be aware of the requirements of a healthy life. If a woman has adequate knowledge, she herself would try to use various preventive measures and would try to get rid of diarrhoea for the safety of family members. Hence the knowledge of women related to health services needs to be updated and improved on a regular basis.

Source of Funding: None

\section{Conflict of Interest: None}

\section{References}

1. Basavanthappa BT. Nursing theories. 1st ed. New Delhi: Jaypee Brothers; 2007;80-6.

2. Basavanthappa BT. Nursing research. 2nd ed. New Delhi: Jaypee Brothers; 2007;100-4.

3. Basavanthappa BT. Child health nursing. 1st ed. New Delhi: Jaypee Brothers; 2015;400-10.

4. Best JW. Research in education. 2nd ed. Philadelphia: FD Davis Company; 2000;205-60. 
5. Bhaduri A, Farrell M. Health research: a communitybased approach. WHO South-East Asian Region Series; 1981. [Google Scholar]

6. Smeltzer SC, Bare B. Brunner \& Suddarth's textbook of medical-surgical nursing. 10th ed. Lippincott Williams \& Williams; 2003;871-4.

7. Patel M. Zinc and ORS supplement. Comm Nurs Spec. 2003;188:63-9.

8. Meshram PV. Use of zinc and ORS for management of diarrhea. Comm Nurs Spec. 2008;56:15-30. 